\title{
Mechanism of Stress-Corrosion Cracking in the AZ3lB Magnesium Alloy
}

\author{
Hugh L. Logan
}

\begin{abstract}
The mechanism of stress-corrosion cracking of annealed AZ31B magnesium alloy in an aqueous $\mathrm{NaClK}_{2} \mathrm{CrO}_{4}$ solution was investigated. Cracking was predominantly an electrochemical process and was shown to be dependent on the rate of strain in the specimen following loading in tension. It is postulated that cracks develop if the protective film on the metal surface is ruptured (over narrow segments of the specimen) at a greater rate than it is repaired in the corroding medium. This would expose film-free metal that is anodic to the filmed metal.
\end{abstract}

\section{Introduction}

An investigation of the mechanism of stresscorrosion cracking of metals, sponsored jointly by the Corrosion Research Council and the National Bureau of Standards, is in progress. Certain of the magnesium alloys are admirably suited for such an investigation. While reports of failure in service are extremely rare, laboratory techniques that will produce stress-corrosion cracking in minutes are well known. As a result, extensive series of experiments can be performed in a conveniently short time.

In earlier work on the AZ31B magnesium alloy in this laboratory [1] ${ }^{1}$ and elsewhere $[2,3]$, it was shown that in certain corrodents a threshold stress could be obtained below which cracking would not occur in 1,000 hr. Above this stress level, specimens would generally fail in less than $5 \mathrm{~min}$. Furthermore, it was found, both in this laboratory and elsewhere, that the threshold stress was procedure sensitive [4]. It was appreciably higher if the specimens were loaded in tension before the corrodent was added than if the specimens were already immersed in the corrodent when the stress was applied. While a threshold stress was readily obtained in laboratory experiments, such threshold stress has not been observed in weather-exposure tests, most probably because these specimens were also subject to general corrosion. Furthermore, there was little difference in average times to failure, at a given stress, whether the specimens were exposed in a marine atmosphere at Hampton Roads, Va., or in an urban atmosphere at the Bureau. It was noted that, in both environments, most failures occurred during or following rain.

Two excellent motion pictures $[5,6]$ showing the stress-corrosion cracking of magnesium alloys have been prepared. Both showed plastic deformation preceding fractures, and Harwood [7] has suggested that some plastic extension must precede stresscorrosion cracking in all materials.

Priest [8] reported that cracking of the AZ61 alloy, once started, could be stopped by the application of cathodic protection. It was considered important to determine whether or not this was also possible with the AZ31B alloy and if so, to see what informa-

\footnotetext{
1 Figures in brackets indicate the literature references at the end of this paper.
}

tion the application of cathodic protection might give as to the mechanism of stress-corrosion cracking: The results of these investigations are reported in this paper.

\section{Materials and Experimental Procedure}

Four lots of the annealed AZ31B alloy material, in two gages, were used in the investigation. The chemical compositions of these materials, as reported by the manufacturers, did not differ appreciably from the nominal composition of aluminum 3.0 percent, zinc 1.0 percent, manganese 0.3 percent, with the impurities iron, nickel, and copper below the maxima permitted in ASTM Specification B9057 T. Both 0.064- and 0.125-in.-gage materials were used; however, most of the work was done with the thicker gage. The materials were machined into $1 / 2$-in. reduced-section tensile specimens. In order to remove any impurities that may have been present on the surface of the sheet as a result of rolling, most specimens were immersed in an aqueous solution containing $30 \mathrm{ml}$ of $\mathrm{HNO}_{3}$ and $10 \mathrm{ml}$ of $\mathrm{H}_{2} \mathrm{SO}_{4}$ per liter until approximately $0.001 \mathrm{in}$. of material had been removed from each face. A few specimens machined from sheet that had been chrome pickled were used with the original surface intact. The specimens were mounted into cells similar to those used in the earlier work [1] and were stressed in tension using lever systems. The corrodent [9] was an aqueous solution containing 3.5 percent of $\mathrm{NaCl}$ plus 2.0 percent of $\mathrm{K}_{2} \mathrm{CrO}_{4}$ used at $30^{\circ} \pm 2^{\circ} \mathrm{C}$.

The threshold stress was determined at $30^{\circ} \mathrm{C}$ for the 0.125 -in.-thick materials, in terms of the percent of yield strength of the individual lots of material. These yield strengths $(0.2 \%$ offset $)$ ranged from 21,900 to $23,100 \mathrm{lb} / \mathrm{in}^{2}$.

In stressing the specimens, they were first subjected to the load of the lever alone, the equivalent stress being 2,000 to 4,000 lb/in. ${ }^{2}$, depending on the specimen thickness. The full load was then added as a unit without impact in 1 to $3 \mathrm{sec}$, thus increasing the stress to the desired value ${ }^{2}$ of 21,500 to $23,000 \mathrm{lb} / \mathrm{in}^{2}$ Wire strain gages attached to opposite faces of specimens, read individually, were used to determine the strain produced in specimens by the addition of both the

2 The lever system used in stressing the specimens had a ratio of 25 to 1 . It was easily possible for one person to apply the full load to the lever without overload
or impact. 
minor and major stresses. As was to be expected, the major strain accompanied the application of the major load. It was noted, however, that specimens exposed in air at $30^{\circ} \mathrm{C}$ continued to extend after loading as long as the stress was applied. For the first few minutes, at any rate, the logarithm of the strain rate decreased linearly with the logarithm of the time.

Wire strain gages, of course, could not be used to determine the strain rate of specimens immersed in the corrodent. It was found, however, that in the strain-rate range that was to prove most important in the investigation (namely less than $500 \times 10^{-6} /$ min) a relationship could be obtained between the strain rate determined using wire strain gages and that computed from dial-gage readings, the dial gage being actuated by the lever system. Thus, it was possible to follow the strain rate of a specimen stressed either in the corrodent or in air (beginning approximately 30 sec after stressing) from periodic readings of a dial gage. It was also possible to follow the strain rate of a specimen to some preselected value, using wire-strain gages, and then rapidly strip off the gages and add the corrodent. The extension at the moment the corrodent was added could be estimated very closely from the extrapolated strain rate-time curve.

\section{Results and Discussion}

\subsection{Specimens Immersed in Corrodent Before Application of Stress}

The strain rate increased markedly as the stress was increased above the threshold value (approximately $95 \frac{1}{2} \%$ of the yield strength). After tabulating the data from many specimens it was evident that if the corrodent was added before the major stress was applied and the strain rate exceeded 500 $\pm 100 \times 10^{-6} / \mathrm{min} 1 \mathrm{~min}$ after the stress was applied, early failure by stress-corrosion cracking was to be expected. If the strain rate had fallen below this value, specimens generally did not fail in 1,000 min and were then removed from the corrodent; the earlier work had shown that if a specimen did not fail in this period it probably would not fail in 10,000 min. The times for failure for the various specimens are plotted against the percents of their respective yield strengths in figure 1 .

In an earlier investigation [10] it was shown that straining of a magnesium alloy above its yield strength ruptured the protective surface film and exposed film-free metal that was approximately 240 mv anodic to the filmed surface. If the stress was held constant so that the strain rate fell off rapidly, the protective film re-formed on the suriace where it had been ruptured.

It is postulated that above the threshold stress and at very high strain rates the protective film is ruptured on most of the surface of the specimen and corrosive attack is of a general nature. As the rate decreases, certain crystals work harden rapidly, the strain rate on them decreases to the point where, with the aid of the $\mathrm{K}_{2} \mathrm{CrO}_{4}$ inhibitor, a stable film is formed. With the average strain rate above

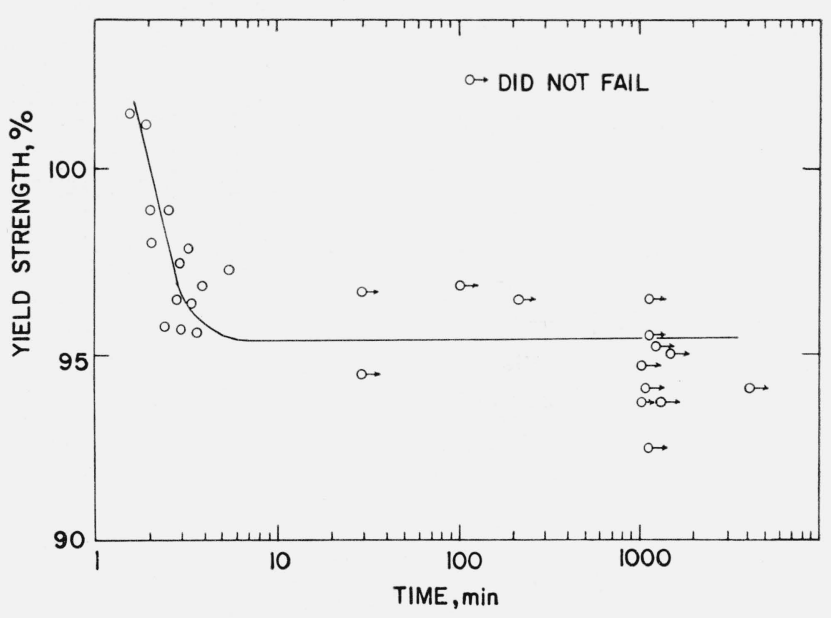

Figure 1. Stress-time to failure curve for two lots of 0.125in.-thick annealed specimens of $A Z 31 B$ magnesium alloy.

The corrodent was a 3.5 percent $\mathrm{NaCl}$ plus 2.0 percent $\mathrm{K}_{2} \mathrm{CrO}_{4}$ aqueous solution at $30^{\circ} \pm 2^{\circ} \mathrm{C}$. Threshold stress was 95.5 percent of yield strength.

$500 \times 10^{-6} / \mathrm{min}$, however, the strain rate will be sufficiently high on other crystals so that the ruptured film over narrow areas perpendicular to the direction of strain will not be repaired. These film-free areas will be anodic to the filmed areas in the $\mathrm{NaCl}-\mathrm{K}_{2} \mathrm{CrO}_{4}$ solution and most probably will be very small compared to the cathodic areas. Electrochemical corrosion will result and unless the strain rate decreases to such an extent that the protective film can re-form, stress cracks will be initiated and rapid failure of the specimen may follow.

If no cracks are formed before the average strain rate falls below $500 \times 10^{-6} / \mathrm{min}$ it is believed that film repair generally is as rapid as film rupture so that stress-corrosion cracking does not occur.

\subsection{Specimens Stressed Before Immersion in Corrodent}

It would be expected, then, that the specimen would not fail if it had been loaded in air and the corrodent was not added until the strain rate had fallen below $500 \times 10^{-6} / \mathrm{min}$. Data indicated, however, that if the specimen had been given the nitric acid-sulfuric acid pickle prior to use, it would fail unless the strain rate had decreased to less than $100 \times 10^{-6} / \mathrm{min}$ before the addition of the corrodent. A typical strain rate-time curve for one of the specimens is shown in figure 2. It is seen that the strain rate increases very rapidly with the addition of the corrodent. The maximum strain rate reached was of course the average over the whole specimen. The subsequent behavior of the specimen indicated that the measured strain was most probably concentrated in short segments. Following this rapid increase in the strain rate, it decreased over most of the specimen length. However, the extension rate was still so high over several short lengths of the specimen that the protective film was not able to re-form and stress-corrosion cracks developed, probably between the 6 th and 7 th $\mathrm{min}$. They had 


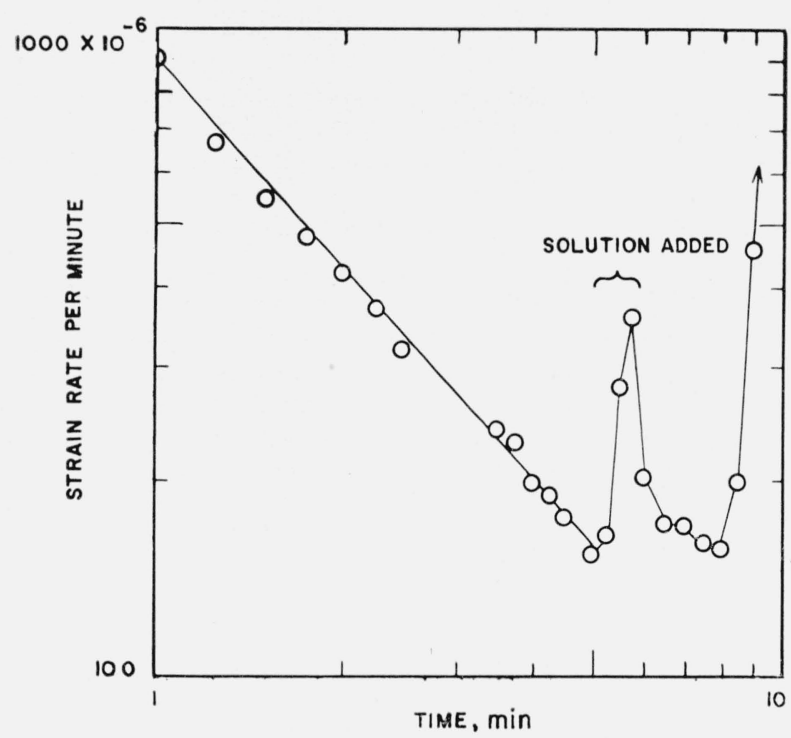

FIGURE 2. Strain rate-time curve for specimen stressed for 5 min prior to addition of solution.

The first increase in strain rate, upon addition of corrodent, is believed to result from escape of dislocations previously blocked by oxide film.

penetrated so deeply by the 8 th min that the average strain rate for the specimen was increasing rapidly and early failure would have occurred had not the stress been removed. Subsequent examination of the specimen showed that the cracks were segregated in several short lengths of the specimen and not more or less uniformly distributed as was the usual case. An anomalous change in strain rate has been reported for polycrystalline iron [11] and for single crystals of cadmium [12] under somewhat similar experimental conditions. No report of such behavior in magnesium alloys has come to the author's attention. If explanations given for other materials are also applicable to this alloy, it is suggested that the escape of dislocations from the metal was blocked by the film formed by pickling in the $\mathrm{H}_{2} \mathrm{SO}_{4}-\mathrm{HNO}_{3}$ solution. Contact of specimens with the corrodent momentarily dissolved this film permitting the escape of trapped dislocations and the subsequent slip of individual crystals with the resulting marked change noted in the rate of extension of the specimen.

The corrodent was added to specimens, machined from a chrome pickled sheet, that were extending at a strain rate as high as $280 \times 10^{-6} / \mathrm{min}$ without subsequent failure. There was no measurable increase in the average strain rate with these specimens when the corrodent was added. At higher strain rates there was apparent dislocation escape at the machined edges with high local strain rates but not appreciable over-all increase in the strain rate. Failures resulted in these instances from cracks penetrating into the metal from the unprotected edges.

From these data, a tentative explanation can be made of the fact that most failures of weatherexposure specimens occurred following rain. It is suggested that solutions formed by water collecting on the specimens would dissolve the oxide film over some areas on the metal sufficiently to permit the escape of block dislocations. This would allow slip on certain microscopic areas and microscopic extension at a sufficiently high rate to initiate stresscorrosion cracking in the rainwater solution. Propagation of the cracks was sometimes stopped by evaporation of the solution before fracture was complete, as is shown in figure 3 taken from the earlior

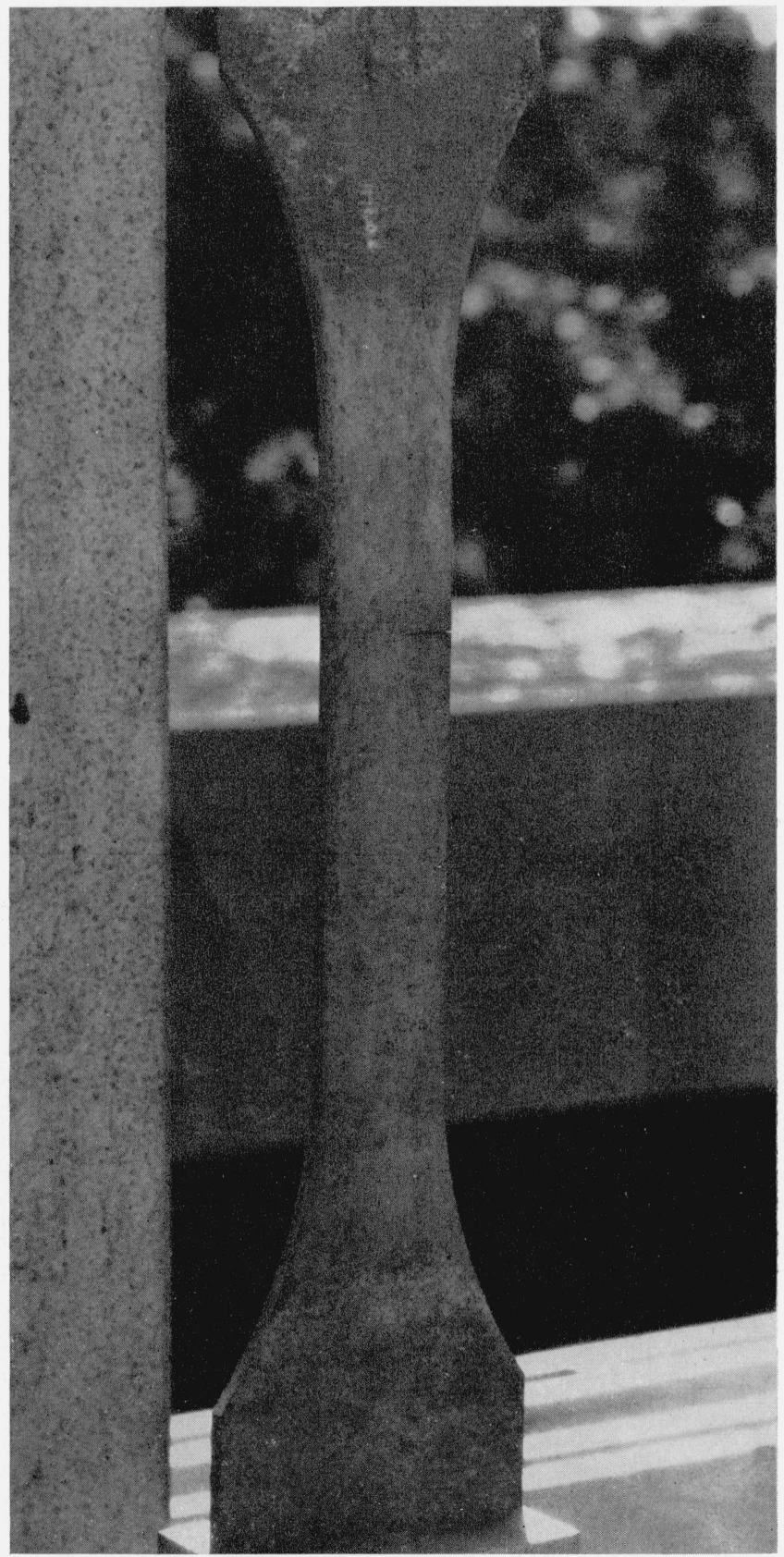

Figure 3. Specimen exposed to weather at NBS. Note stress-corrosion crack extending about $1 / 3$ through specimen.

Cracks of this type, found after rain, are believed to have been initiated by microscopic strain after dissolution of the oxide film by the rainwater-corrosion product solution which permitted the escape of blocked dislocations. Propagation of the cracks continued in this solution until failure occurred or evaporation of the solution stopped the reaction. 
paper [1]. In many cases, however, specimens were found to have failed completely after a rain.

\subsection{Effects of Cathodic Protection}

The effects of the application of cathodic protection to a specimen in which stress-corrosion cracks are developing offers much information as to the mechanism of the corrosive process. It was determined that 0.125 -in.-thick specimens stressed to $98.6 \pm 0.4$ percent of their yield strength would fail in an average period of $152 \mathrm{sec}$ (standard deviation $39 \mathrm{sec}$ ). Cathodic protection ${ }^{3}$ was applied to other specimens subjected to the same stress after exposure periods of 90 and 105 sec. A typical strain rate-time curve for these specimens is shown in figure 4. Examinations, using a binocular microscope, of specimens that had been removed from the corrodent after 35 to $40 \mathrm{sec}$ exposure (stressed to 98.5 to $99 \%$ of the yield strength) indicated that cracking began during this interval. Hence, it is logical to assume that stress-corrosion cracking is an important factor in the increase in the extension rate as shown in figure 4 after $1 \mathrm{~min}$ of exposure. The marked change in extension rate with the application of cathodic protection (at a current density of $0.5 \mathrm{ma} / \mathrm{cm}^{2}$ over the exposed area) indicated that cracking was almost if not completely stopped. This is substantiated by the fact that a specimen subjected to the conditions described above had not failed in $20 \mathrm{hr}$ although it had extended about 0.04 in. Figure 5 shows the total extension and potential curves, for this specimen, plotted against

\footnotetext{
${ }^{3}$ A cylindrical anode of stainless steel was placed around the inside of the cell. The ends of the specimen were masked off with "Duco Cement" so that only $15 \mathrm{~cm}^{2}$ of the reduced area of the specimen was exposed to the corrodent.
}

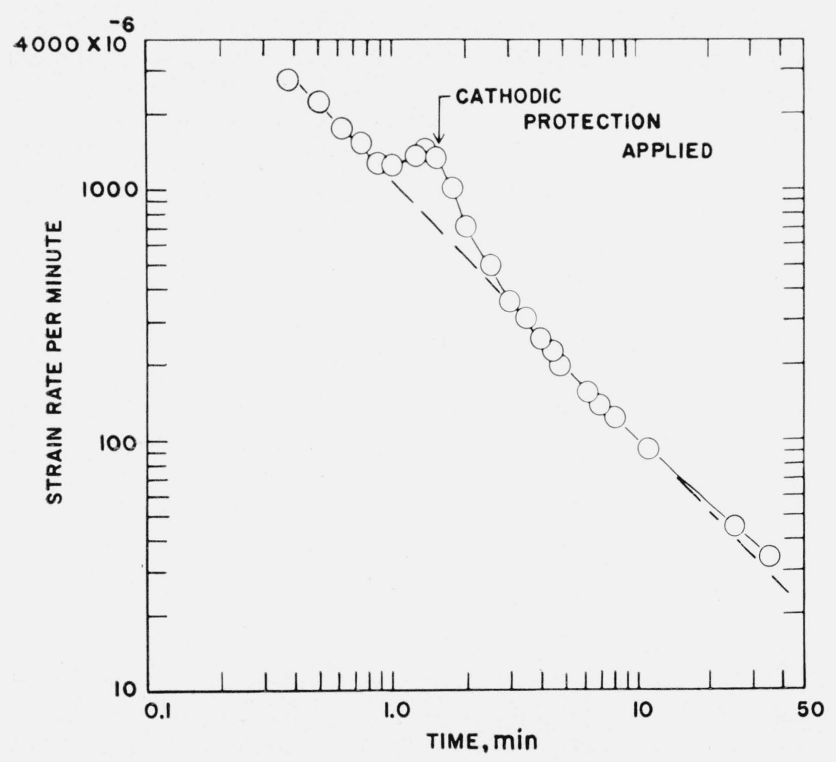

Figure 4. Extension rate-time curve for specimen stressed to approximately 99 percent of its yield strength.

Deviation of the curve from a straight line (after $1 \mathrm{~min}$ ) was due to development of stress-corrosion cracks. (First cracks develop in 0.6 to $0.67 \mathrm{~min}$ ). The application of cathodic protection stops the crack propagation; after 3 min the extension rate was approximately that to be expected had no cracking occurred. the time just before and immediately following removal of the cathodic protection. It is seen that the specimen began to extend rapidly within $2 \mathrm{~min}$ after the protection was removed. It would have failed within another minute had not the stress been removed. There was no lasting polarization of the specimen as the result of cathodic protection. With its removal, the potential of the specimen immediately became approximately $400 \mathrm{mv}$ more positive than it had been before protection was applied. The potential soon changed to the nominal value of $-1.5 \mathrm{v}$ and as the extension of the specimen opened up stress-corrosion cracks and exposed unfilmed metal, became still more negative.

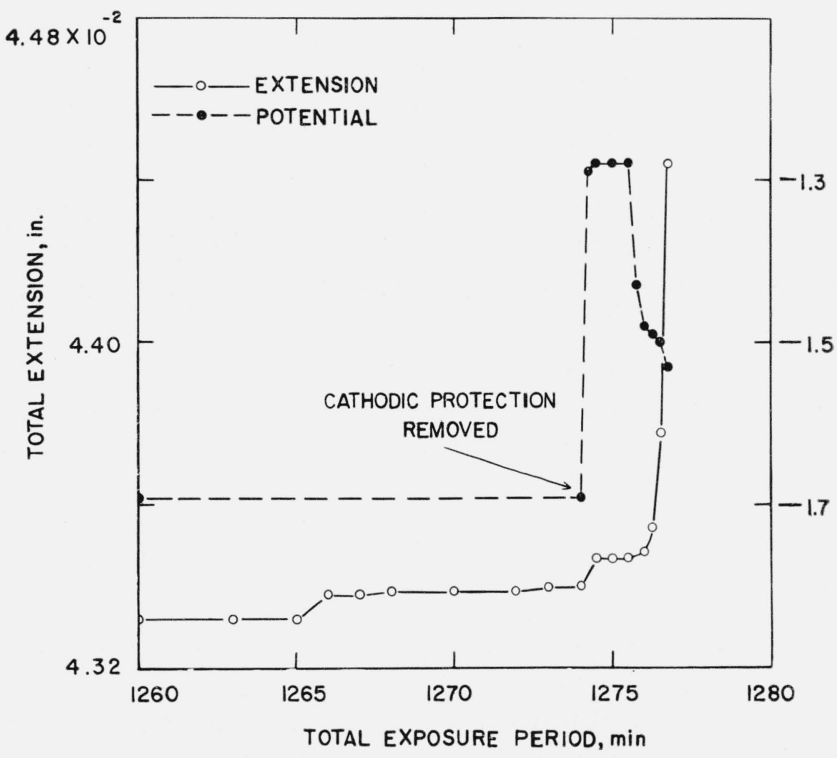

Figure 5. Total extension-time and potential-time curves for specimen after immersion for 1,260 min in the corrodent.

Note the change in potential with the removal of cathodic protection. Nominal potential of material with respect to a saturated calomel electrode was -1.50 $v$. The increase in extension rate after the removal of cathodic protection indicated that early failure of the specimen would have occurred had the stress not been removed.

The fact that stress-corrosion cracking can be stopped by the application of cathodic protection and that it will start again after the removal of this protection indicates that, in this alloy at least, it is primarily electrochemical. Specimens removed from the solution after the application of cathodic protection, contained cracks as is shown in figure 6 . The depths to which cracks penetrated into the metal were determined on longitudinal metallographic sections taken well away from the edges. Maximum crack depths were determined in 0.125-in.-thick specimens to which protection was applied after $90 \mathrm{sec}$ and in 0.064-in. specimens to which the protection was added after 60 to 65 sec. Cracking was assumed to have started in each case after 35 sec exposure. Penetration rates for some of the deeper cracks amounted to $4 \times 10^{-4} \mathrm{in} . / \mathrm{sec}$. In the average exposure periods to failure for the two thicknesses of specimens, the penetrations would be approximately 0.02 and 0.047 


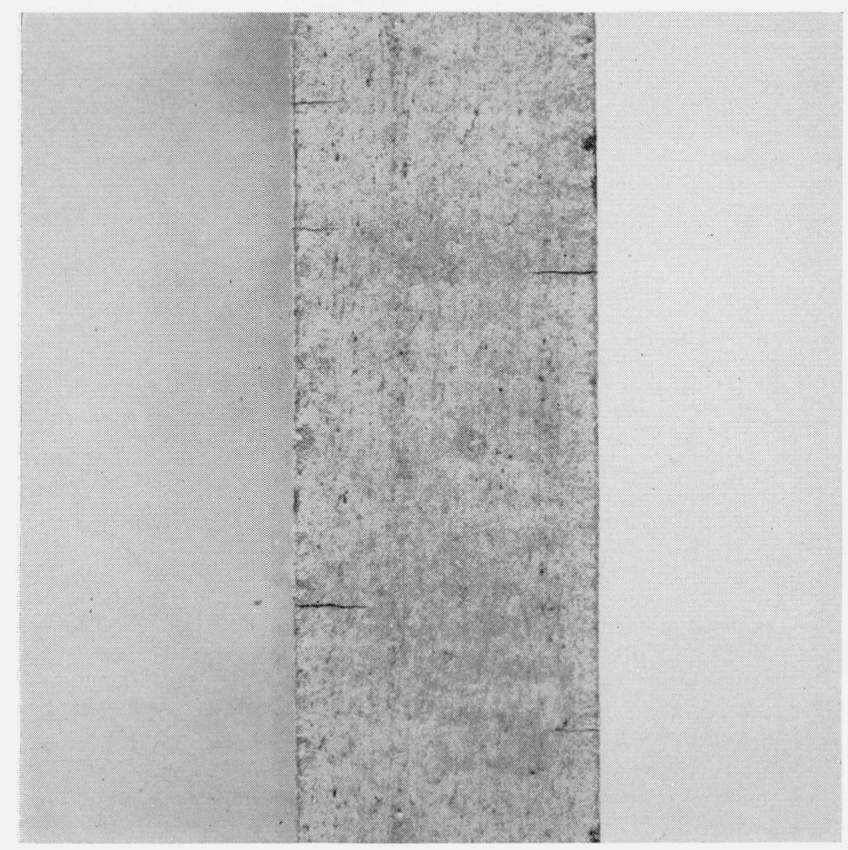

Figure 6. Edge of specimen given cathodic protection $80 \mathrm{sec}$ after application of major load.

Cracks extending into specimen from edges are believed to have developed in period between 35 th and 80 th sec after loading. Specimen was removed from corrodent after approximately $18 \mathrm{hr}$ exposure. $\times 10$.

in. for the 0.064 - and 0.125 - in. specimens, respectively, i. e., 30 to 37 percent of the thickness of the specimens. Satisfactory measurements of the depth of penetration of the stress cracks at the point of failure are difficult to make, in that failures frequently result from a crack or cracks that penetrated into the specimen simultaneously from an edge and the opposite faces. It is believed that the weakening of the specimen by stress-corrosion cracks, to the point where it will fail by tensile fracture, resulted from penetration of the cracks at the rate indicated above, and was therefore primarily electrochemical.

\subsection{Current Density Associated With Stress-Cor- rosion Cracking}

If it can be assumed that Faraday's law applies to the dissolution of a metal as well as to its deposition, and if the electrochemical equivalent of the alloy is then taken to be the same as that for magnesium, the current density necessary to produce a crack penetration of $4.0 \times 10^{-4}$ in./sec may be easily shown to be approximately $14 \mathrm{amp} / \mathrm{cm}^{2}$. It should be noted that this calculation assumes only that the anodic reaction is 100 percent efficient; it requires no assumptions as to the width of the anodic area at the tip of the crack. If the anodic reaction is even in part,

$$
\mathrm{Mg}=\mathrm{Mg}^{+}+e,
$$

as has been suggested by Hoey and Cohen [13] and others instead of the conventional

$$
\mathrm{Mg}=\mathrm{Mg}^{++}+2 e,
$$

the current density requirements are materially reduced. They are, however, much higher than any that have come to the author's attention for other materials. Hoar and Hines [14] estimated that a current density of $1.5 \mathrm{amp} / \mathrm{cm}^{2}$ would account for the rate of crack penetration $\left(2.2 \times 10^{-5} \mathrm{in} . / \mathrm{sec}\right)$ that they found in austenitic stainless steel in a boiling 42 percent $\mathrm{MgCl}_{2}$ solution. They further report that under certain conditions, iron can be anodically dissolved at five times the rate of propagation of the cracks in the austenitic stainless steel reported above.

It is the author's experience that the stresscorrosion cracking of austenitic stainless steels in a boiling 42 percent $\mathrm{MgCl}_{2}$ solution is a very much slower process than that of the AZ31B alloy in the $\mathrm{NaCl}-\mathrm{K}_{2} \mathrm{CrO}_{4}$ solution. No failures of 0.064-in.thick stock of type 304 stainless steel have occurred in this laboratory in less than $1 \mathrm{hr}$, although cracking is believed to have been initiated in less than $30 \mathrm{~min}$.

The $\mathrm{NaCl}-\mathrm{K}_{2} \mathrm{CrO}_{4}$ corrodent had a specific resistance of $11 \mathrm{ohm} \mathrm{cm}$; with a difference in potential between the cathodes and anodes of less than $1 / 2 \mathrm{v}$, it is seen that the cathode areas must be largely within the cracks if a current of the magnitude indicated above is to flow. The motion pictures mentioned above showed copious quantities of gas (probably hydrogen) escaping from the stresscorrosion cracks which would also indicate that the cathodes were located primarily on the sides of the cracks.

\section{Summary}

1. A study has been made of the mechanism of stress-corrosion cracking of the AZ31B magnesium alloy in an aqueous solution containing 3.5 percent of $\mathrm{NaCl}$ plus 2.0 percent of $\mathrm{K}_{2} \mathrm{CrO}_{4}$.

2. Specimens dead loaded in tension by means of lever systems continued to extend for an appreciable time following stressing. Specimens stressed in the corrodent and extending at an average strain rate in excess of $500 \pm 100 \times 10^{-6} / \mathrm{min}, 1 \mathrm{~min}$ after the stress was applied, generally failed in less than $5 \mathrm{~min}$ by stress-corrosion cracking. Specimens extending at a slower rate, in most instances, did not fail in 1,000 $\min$.

3. The strain rate for specimens stressed above the threshold stress prior to immersion in the corrodent must fall appreciably below $500 \times 10^{-6} / \mathrm{min}$ or the specimens will fail. The strain rate on addition of the corrodent depended on the surface condition of the specimen. It was suggested that the addition of the corrodent to specimens, pickled in the $\mathrm{H}_{2} \mathrm{SO}_{4}-\mathrm{HNO}_{3}$ solution, permitted the escape of blocked dislocations and an appreciable increase in the average strain rate. Escape of dislocations from abraded or chrome pickled surfaces was prevented (except in some highly localized areas) and no increase in the average strain rate was noted. 
4. The advancement of stress-corrosion cracks was halted for at least $20 \mathrm{hr}$ by the application of a cathodic current of $0.5 \mathrm{ma} / \mathrm{cm}^{2}$ of exposed area. With the removal of cathodic protection, stresscorrosion cracking continued so that the total time to failure (without protection) was little, if any more, than would have been required had the process not been interrupted by the application of cathodic protection.

5. The evidence indicates that stress-corrosion cracking of the AZ31B alloy is primarily an electrochemical process. Segments of a stressed specimen are strained at a higher-than-the-average rate so that the protective film on these crystal surfaces ruptured by the first strain is not repaired. These film-free surfaces are anodic to surfaces on which film repair has taken place. An electrochemical reaction occurs with very rapid attack at the anodes. This forms a groove or notch at the anode and acts as a region of stress concentration so that the material at the tip of the notch can continue to extend at stresses lower than the initial stress. The protective film does not re-form on these areas and the crack propagates primarily by the electrochemical action until failure occurs.

6 . If it is assumed that the alloy has the same electrochemical weight as magnesium, it is calculated from crack-penetration rates that there is an effective current density of $14 \mathrm{amp} / \mathrm{cm}^{2}$ at the crack tips.

7. It is suggested that the effect of rain on weatherexposure specimens was to form a solution with the corrosion products that would permit the escape of dislocations and hence the rapid extension of microsegments of the specimen as described in 3 above. This would result in partial or complete failure in the rainwater solution by the process postulated in 5 above.

\section{References}

[1] H. L. Logan and H. Hessing, Stress corrosion of wrought magnesium base alloys, J. Research NBS 44, 233 (1950) RP2074.

[2] W. S. Loose and H. A. Barbian, Stress corrosion testing of magnesium alloys, Symposium on Stress Corrosion Cracking of Metals, ASTM, AIME, p. 273, 1944.

[3] R. B. Mears, R. H. Brown, and E. H. Dix, Jr, A generalized theory of stress corrosion of alloys, Symposium on Stress Corrosion Cracking of Metals, ASTM, AIME, p. 323, 1944.

[4] W. S. Loose, private communication.

[5] D. K. Priest, Motion picture of stress corrosicn cracking of magnesium alloy; D. K. Priest, F. H. Beck and M. G. Fontana, Trans. ASM 47, 473 (1955).

[6] R. D. Williams, Film produced by Aluminum Companv of America Research Laboratories. Shown NACE Conference March 16, 1954 (Kansas City, Mo.).

[7] J. J. Harwood, The phenomena and mechanism of stress corrosion cracking, Stress corrosion cracking and embrittlement, p. 1 (edited by W. D. Robertson, John Wiley \& Sons, Inc., 1956).

[8] D. K. Priest, The mechanism of stress corrosion cracking observed in a magnesium alloy, Stress corrosion cracking and embrittlement, p. 81 (edited by W. D. Robertson, John Wiley \& Sons, Inc., 1956).

[9] G. F. Sager, R. H. Brown, and R. B. Mears, Tests for determining susceptibility to stress corrosion cracking, Symposium on Stress Corrosion Cracking of Metals, ASTM, AIME, p. 255, 1944.

[10] H. L. Logan, Film-rupture mechanism of stress corrosion, J. Research NBS, 48, 99 (1952) RP2291.

[11] C. S. Barrett, An abnormal after-effect in metals, Acta Met., 1, 2 (1953).

[12] C. S. Barrett, After-effects in polycrystalline cadmium. Trans. AIME 19\%, 1652 (1953).

[13] G. R. Hoey and M. Cohen, Corrosion of anodically and cathodically polarized magnesium in aqueous media, J. Electrochem. Soc. 105, 245 (May 1958).

[14] T. P. Hoar and J. G. Hines, The stress corrosion cracking of austenitic stainless steels, J. Iron Steel Inst., 182, 124 (1956).

Washington, August 20, 1958. 